\title{
Article
}

\section{Heart of Gold: Fact and Mysticism in Documentary Form}

\author{
Knudsen, Erik \\ Available at http://clok.uclan.ac.uk/15544/ \\ Knudsen, Erik ORCID: 0000-0001-8361-6975 (2007) Heart of Gold: Fact and \\ Mysticism in Documentary Form. Journal of Media Practice, 8 (1). 49 - 61. ISSN \\ $1468-2753$
}

It is advisable to refer to the publisher's version if you intend to cite from the work. http://www.tandfonline.com/doi/abs/10.1386/jmpr.8.1.49_1

For more information about UCLan's research in this area go to http://www.uclan.ac.uk/researchgroups/ and search for < name of research Group>.

For information about Research generally at UCLan please go to http://www.uclan.ac.uk/research/

All outputs in CLoK are protected by Intellectual Property Rights law, including Copyright law. Copyright, IPR and Moral Rights for the works on this site are retained by the individual authors and/or other copyright owners. Terms and conditions for use of this material are defined in the policies page.

\section{CLoK}

Central Lancashire online Knowledge www.clok.uclan.ac.uk

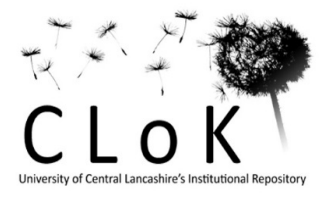




\title{
HEART OF GOLD \\ Fact and Mysticism in Documentary Form \\ A Research Report \\ Dr Erik Knudsen
}

\author{
KEYWORDS \\ Documentary, practice, story-telling, fact, fiction, Africa
}

\begin{abstract}
This report seeks to summarise the process and outcomes of a practice based research project funded by the Arts and Humanities Research Council and undertaken during the academic year 2005/2006. The primary outcome of the project is the film Heart of Gold $(40 \text { minutes })^{\mathrm{i}}$ and the purpose here is to augment and expand this primary outcome.

Heart of Gold is a documentary project which took me, the filmmaker, back to my country of birth, Ghana, to explore how traditional story-telling may help shape a new approach to documentary forms. The documentary revolves around the changing relationship local people have to the precious and mystical metal, gold. By exploring this changing relationship, the aim was to discover what kind of stories are told about gold, how these stories are told, and how these stories and their mode of delivery may help the filmmaker create documentary narrative approaches which can encompass both realism and mysticism.
\end{abstract}

The aims and objectives of the project, its process and outcomes, are described here and key answers identified with a view to encourage further exploration and debate.

\section{FILM SYNOPSIS}

Set in the Akim Abuakwa region of Ghana, Heart of Gold is a poetic documentary ${ }^{\mathrm{ii}}$ exploring the changing relationship people in the region have with gold. Traditionally considered to possess a spirit like any other sentient being, gold has played an important part in the history and mythology of Ghana. This is still evident today, though this relationship is rapidly changing, as gold becomes a crucial part of the Ghanaian economy, controlled almost exclusively by multi-national companies.

By treating the mythology as equally factual as the observed empirical world, Heart of Gold is built on stories told by various people in the Akim Abuakwa region and these stories are woven together by an over-arching story of a young boy who finds a lump of gold in the river Brim and wonders what to do with it. This quest leads him to meet a number of people and have a number of experiences which enlighten us to the spiritual relationship that people still have with gold. 
The film freely and seamlessly mixes what we normally think of as documentary and fiction into a unique form which is hoped will allow the audience to understand the themes in a way that goes beyond the psychological and allows us to glimpse the transcendental realism of the story and its themes

Featuring the local school boy, Kwasi Akufo, as the main character, others appearing in the film include a retired jeweller, a chief's elder spokesman, a fetish priestess, 'galamsay' miners and other people from the small town of Kibi, situated in the heart of the region.

\section{QUESTIONS AND PROBLEMS}

At the heart of the research project were a number of problems and issues which I felt needed looking at. Pondering these problems and issues, I concluded a series of aims and objectives which necessitated that this research needed to be carried out as practice research. These problems, issues, contexts, aims and objectives can be summarised as follows:-

\section{Aims \& Objectives}

- To research alternatives to the empirical and factually based classic documentary narrative's approach to story telling.

- To examine how such alternatives can reveal different aspects of human experience not generally revealed by these classic approaches; in particular, to explore the relationship between fact and mysticism.

- To identify practical ingredients which could form the basis for cinematic practitioners to further evolve non-empirical approaches to making documentary films.

- To create practice based work - a documentary film - which reveals, illustrates and exemplifies the findings.

- To explore African modes of story-telling, in particular modes in which reality and mysticism blend.

- To create a documentary practice outcome, whose form and approach can shed new light on the plight of aspects of African life.

- To write and publish a refereed article based on research findings.

\section{Research Question or Problem}

There are aspects of human experience that are not adequately dealt with, or revealed, through classic documentary narrative paradigms. These are questions which can only be adequately explored through practice and through this practice the intention is to explore the following questions:-

First research question: How can one employ a practical approach to cinematic documentary narrative which goes beyond the dominant paradigm exemplified by 
elements such as cause and effect, conflict and resolution, and psychologically explicable situations, character motivations and narrative motivations, to reveal qualities of spirituality and transcendence without reducing these elements to fit a paradigm that ultimately contradicts the very nature of these transcendental and spiritual qualities? Within this context, how can one practically create a cinematic documentary narrative that is essentially driven by the experiential rather than by meaning, representation or the illustrative?

Second research question: How far can visual imagery, colours, shapes, objects, camera angles and sound be used to bring to life the essence of predominantly oral African storytelling traditions to reveal non-materialistic perspectives on life and living? Such African traditions often freely, and equally, mix what we in the developed world think of as separate incongruous elements, such as reality, fact, superstition, myth, fantasy, spiritual reality. While certain genres within fiction may bring together some of these elements in an agreed fictional paradigm, how can one bring such elements together within a paradigm of fact?

Third research question: By focusing the subject matter of the documentary practice output on the changing relationship of local people in the Akim area of Ghana - known for its abundant gold, yet still materially poverty-stricken - how can one create a documentary narrative about such a relationship seamlessly and equally incorporating such elements as fact and fiction, reality and fantasy, the material and the spiritual, hope and despair and bring to life a living metaphor, without reducing the form to social realism?

\section{Research Context}

What defines the documentary genre is also at the root of its limitations; an epistemology which ties it to the factual or empirical experience of life. While in early British documentary, there were some attempts to discover the poetry of documentary (Humphrey Jennings, for example) much of contemporary documentary is confined to a perspective on life in which the factual is primarily what can empirically be observed, then supported by the psychologically explicable. Social realism, observational documentary and interview-based documentary are examples of variations of a genre which broadly lives within the same classical paradigm of cause and effect, conflict and resolution.

There are a number of, usually, non-UK examples of documentary which have attempted to break away from this paradigm: the late Jean Rouch, for example, whose work in Africa - in fact in Ghana - shows how the documentary has the potential to go beyond the material surface of the world to reveal a spiritual dimension; or Dvortsevoy, whose work Bread Day or In The Dark sees him move away from any notion of cause and effect, conflict and resolution in order to reveal a dimension of life which social realism cannot adequately reveal or portray.

While most of the world rushes headlong into embracing a largely materialistic engagement and perspective on life, some parts of the world still have remnants of cultures in which the spiritual, the mental and the physical occupy equal status in 
epistemology. Though, increasingly, Africa, too, is part of these developments, the difficult postcolonial era sees it struggling to fully achieve western ideologies and values. Many in the West look to places like Africa to re-discover spiritual identities which have been lost in our predominantly materialistic world, but perhaps we don't have the tools, the language, the story-telling mechanism to reach this epistemology some long for. In African and Latin American literature, we often hear commentators from the developed world using terminology such as 'magical realism' to describe this seamless blending of realism, mysticism, magic, fact, history, politics and morality in the creation of cultural product.

Arguably, British documentary is in decline, in terms of the breadth and depth of what is produced. The commercial climate of contemporary television, the traditional funder of much important documentary work of the past, has seen an increased dependence on formulas which reinforce the need for drama, conflict and explicable cause and effect in most documentaries. The HE context provides one of very few contexts within which the exploring filmmaker can seek to expand and develop the language of film.

\section{RESEARCH PROCESS}

Gold was chosen as the inroad into the research theme because it is an inanimate object to which we, in the developed world, largely have a materialistic relationship. Yet in a country like Ghana, traditionally as well as currently, it is considered a living entity with a spirit, just like the human being, and is not merely considered a material object. It is both, simultaneously. Being half Ghanaian myself, I knew this from the outset. In the microcosmic relationship to gold, I hoped to be able to immerse my research in the macrocosmic perspective that truly reflected this paradoxical relationship to nature and life, in which the inner spiritual world and the outer material ${ }^{\mathrm{iii}}$ world coexist at least as equals, if not as one and the same.

To this end, I could not simply bring the materialistic, socio-political or psychological paradigms of the developed world to use as tools of deconstruction or analysis. I wanted to delve beyond these paradigms and truly immerse myself in the 'real' world of the place and its people. As my research confirmed for me, this 'real' world is, indeed, a world where what we, in the developed world, might call myth, legend, fantasy, magical and so on is as 'real' as the physical reality of the material, the political and even the psychological.

Many films have been made about the materialistic plight of Africa and Africans usually based on our aspirations and value systems - and about the anthropological curiosity that primitive cultures present us with - usually, looking in, 'objectively', from the outside. So, it was clear from the outset that the film was not going to follow the pattern of so many others by looking at predominantly the material situation around gold. In other words, I was not going to be tempted to make a film around the economic, social and political history of injustices around resources. However, given that this, too, is part 
of the reality, I would have to find another way of touching on this aspect of the reality without it betraying the overall perspective.

This had an impact on the nature of my research, as did the fact that one of my key research objectives was to understand how stories reflect the 'paradoxical' world of spirit and matter and how these stories could be of use to me as a filmmaker in terms of representing reality.

Though I did carry out some textual background research on gold and African storytelling in general, the bulk of my research was primary qualitative research in the form of interviews with a range of Ghanaians in the region of Akim Abuakwa. It is these stories of myths, legends and actual experiences that form the basis of the entire research project.

These interviews were carried out predominantly during the month of January 2006 and many of them were documented on camera. My inroad into the communities was usually through the local Chiefs, who would themselves initially tell me things then pass me on to others in the community who would tell me stories and experiences. Interestingly, it was almost always men ${ }^{\text {iv }}$.

I was also able to draw on the expertise and experience of a number of people from outside the region, many of whom were also interviewed on camera and some of whom appear in the film. Doris Adabasu Kuwornu, my Ghanaian co-producer and Head of Programmes at Ghana Broadcasting Corporation, was invaluable in introducing me to the right people and helping me identify some common threads; Dr Yaw Graham, musicologist, was able to give valuable insights into the psyche of Ghanaian culture; Dr Yao Graham, Director of the lobby organisation Third World Network - Africa was very useful in terms of highlighting the socio-political situation around gold; and Kwaku Nkrumah, retired GBC Regional Director, with three decades as a journalist, correspondent and documentary maker, was able to help me immensely on the ground.

These meetings with people took me to many locations, including active and disused mines, towns and villages where gold mining was a strong feature, farms where galamsay $^{\mathrm{V}}$ miners mine, rivers where gold is abundant and so on.

Following a month of researching along these lines, I returned to the UK to reflect on my findings and to explore ways of making the documentary. Some of the material I had shot on my research trip was to be used and I developed a treatment. This treatment was in part based on this material, but also necessitated a second trip to Ghana. I returned to Ghana in late March for a 2 week period, during which time I shot more specifically for the film. I also commissioned a Ghanaian composer and musician, Lionel Lawson, to write some specific music for the film, which I shall briefly discuss later.

The whole research process was, in a sense, a process of direct discovery based on personal encounters ${ }^{\mathrm{vi}}$. 


\section{RESEARCH OUTCOMES}

The primary outcome, as mentioned, is the film Heart of Gold. The findings, in relation to the research questions, should spring directly from the film. Here I mainly seek to point the reader to some of the key elements which follow as a consequence of my findings. This is not meant to be an explanation or an analysis, as I fear such an endeavour would reduce the film to something it is not, thereby destroying it. First and foremost the film is meant to be experienced as a whole, the less with the intellect and the more with feeling, the better.

Accompanying the film on the complete DVD, are some of the interview extracts from my initial research. I have concentrated on interview extracts from people who actually appear in the film in one form or another. It is hoped that the viewer who wishes to understand more about how I arrived at the finished outcome of the film will be able to make connections between these additional interview extracts and the film itself and from that juxtaposition get a strong sense of how the film has become what it is.

I shall briefly outline some key themes ${ }^{\text {vi }}$ that emerged, then sketch briefly how I have sought to work with these in the film, bearing in mind my research questions.

- Divinity, and divine purpose, are at the heart of every story and experience conveyed. It is tempting to look at this from the scientific dogma of the developed world as a psychological or cultural phenomenon, with little basis in fact. However, to the traditional Akan, divine purpose is a fact with plenty of evidence to support it.

- Everything has a spirit directly connected to the divine; matter, plant and sentient beings alike. There is no distinction, no divisions, and the spirit that lives in gold is as important as that which lives in a human. As an extension of this, spirit can take many forms and even transform itself - a central feature of story-telling.

- Given the facts of divine purpose and the spiritual presence in everything, the relationship with nature is one of respect, caution and humility. The actions of nature and the actions of the divine are one and the same, consequently nothing is coincidence and the interaction between the human and all aspects of nature are aspects of spiritual interaction. For example, fortune and misfortune are not random events, but often divine intervention. What for us in the developed world may be called superstition, is for the Akan an intricate connection of interacting forces $^{\text {viii }}$. Likewise, the attitude to how resources are used, how herbal medicine is used and the attitude to the dead and yet to be born ties in with this system. As Dr Dartey Kumordzi says in Heart of Gold: 'Everything is God'.

- The oral story is at the heart of all communication about the spiritual, moral, social and historical aspects of life.

- While some stories one could describe as legend or myth - in other words, they are stories that have been handed down through generations - other stories relate to direct personal experience. In both cases, no distinction is made between what we in the developed world may consider fact and fiction, reality and fantasy or real and unreal. Listeners of the story consider everything to be fact ${ }^{\mathrm{ix}}$. (When 
being told a personal account, for example, that included what for me were quite fantastical elements, I had to ask myself: who am I to dispute what this person is telling me is a true personal experience? I had to open my mind and say, just like my story-teller and his listeners: if it is so, it is so.)

- Stories were usually wrapped in the context of a moral and a blessing. This, I discovered, is important; for a story is not merely told to entertain, but to educate, enlighten, forewarn, encourage or to reflect philosophically. Every story has a clear purpose, of which the story-teller is well aware, and that purpose is connected to the divine.

- Usually stories involve many elements of nature and are not just confined to human interactions. It is tempting to look at this as a representational issue of metaphors, but for the Akan, where everything, including matter, has a spirit and a will, one would be missing an essential ingredient to full understanding.

It is clear, that if one wants to show the real factual world of an Akan, to merely make some sort of film observing this world from the outside - using the paradigms of Western science, psychology an anthropology - we would see a very different world; one that would, perhaps, only ultimately reinforce our own world view, one that would reinforce our notions of distinctions of progress and development.

Though I am, in part, Ghanaian, I am culturally more European ${ }^{\mathrm{x}}$. I can only partially immerse myself in the mindset of the Akan. In making Heart of Gold, therefore, it was not merely a question of recreating some fantastical narrative and then claiming it to be real. What I was concerned with was how could I evolve my essentially European form of so called factual representation into a form that allows a genuine entry into the real world of the Akan.

\section{Fact and Fiction}

To blend the factual and fictional genres is popular in contemporary British television. Usually promoted under the banner of 'ground-breaking documentary', there are common features which, ironically, actually reinforce the distinctions between the two genres. Such programmes ${ }^{\mathrm{xi}}$ are usually claiming to be based on empirical facts (right at the core reinforcing the world view that some things are facts and others imagination); they point to specific factual events employing techniques which reinforce the perceived divisions between fact and fiction. For example, the use of authoritative narration over action which adheres strictly to the conventions of drama; the use of expert and star personalities, again in the context of conventional drama or special effects events; and the use of traditional interview conventions to link conventional dramatic reconstructions. The traditional conventions of both drama and documentary are actually reinforced to ensure that the viewer is reassured that these distinctions do exist. These are some ways in which the style of these blends actually serve to reinforce the belief system of the makers, in that it reaffirms the notion that the real and the imaginary are separate.

Rather than bring together - by accentuation - two distinct genres, in Heart of Gold I have sought to dissolve the notion of fact and fiction. Everyone in the film is themselves 
and know each other in real life, as they do in the film. I have seamlessly interwoven footage that I have constructed with footage that I have observed; footage of interviews have been incorporated into sequences I have partially constructed; improvised sequences where participants interact around stories they told me; recreations of impressions and stories constructed; and natural phenomena have been assimilated with actuality and constructed sequences ${ }^{\mathrm{xii}}$.

Let me briefly describe the construction of three scenes, by way of example. First example: there is a scene in which the local boy, Kwasi Akufo, goes to show some local galamsay miners the lump of gold he has found in the river. I had interviewed the galamsay miners on camera, during which they had told me about their mining and various stories and experiences around gold. For the film, I arranged for the boy to come and show them this lump of gold while they were mining. I asked them, when he arrived, to stop mining and tell him some of the stories they had told me. With little direction, I asked them to repeat this a couple of times, enabling me to capture the scene from a couple of angles. What resulted was a scene consisting of a mixture of actuality, improvisation, directed performance and factual recounting.

Second example: there is a scene in which Kwasi returns to his home and finds no one there. He turns on the TV while contemplating his lump of gold. On the TV, there happens to be a programme in which Dr Yaw Graham is being interviewed about the historical and socio-political situation around gold production. This interview includes archive footage of commercial mining. The interview itself is footage I shot during my research. This has been planted in the TV and used within the context of a constructed scene.

Third example: there is a scene where Kwasi has returned to the river where he found the gold and is acutely aware of nature around him. He falls asleep and while asleep, there is a total solar eclipse. Hearing his name whispered in the wind during total darkness, he awakes just as it starts to get lighter and sees a man pouring libation in the river. The natural phenomenon and the man pouring libation was actuality, while the action with the boy was constructed within that actuality.

Suffice to say, that the idea was to seamlessly weave process and form to create a work that transcends genre definition; form and subject as inseparable as possible in order to truly reflect the inseparability of my themes of matter and spirit, real and imaginary, fact and fiction.

\section{Character and Motivation}

I chose to have a young boy in the film and went to a local school to cast Kwasi Akufo (13 years old). He was a boy who had had no experience whatsoever of drama or film performance. His personality was like the personality in the film and provided me with an opportunity to have a 'blank canvas' ${ }^{\text {xiii }}$; no presumptions about process, little knowledge about the subject and its themes, impressionable, open, innocent and his face and mannerisms devoid of psychological clues. I felt that this 'blank canvas' was needed for 
the other elements of the story to be 'painted' onto this boy, for intangible expressions to find their way through him.

A key feature of Kwasi's performance was that I wanted to strip the character and his motivations of all psychologically explicable motivations, in order to, in a sense, allow other forces to act on him. The classical narratives of both documentary and fictional genres requires psychological motivations, but when dealing with realities in which divine motivation, or so called coincidences, are in themselves forces for action, it seemed important to take steps to try to eliminate elements that could reduce the narrative's motivational forces to the cause and effect of psychology.

The overarching story that binds Kwasi's experiences was loosely based on a number of stories I had been told about children finding gold. There is a narrative motivation, but it is as simple as I could muster: a boy finds a lump of gold in the river Brim and doesn't know what to do with it. As a consequence of this, he goes to see a number of people, who tell him stories about gold, and he has a number of experiences with the gold. At the end he comes to a decision, but the motivation for this decision is influenced by factors beyond what is causally or psychologically explicable; it is, simultaneously, both mystical and practical, influenced by realities and perceptions I have tried to identify earlier.

\section{Narrative Purpose}

I have tried to incorporate a sense of moral purpose into the form of the film, as this seems to be a feature of almost every story I was told about gold; in other words, not merely that the subject matter or the story reveals a moral purpose, but that the storytelling mode - the form - itself reflects a morality. The boy's story, with its ambiguous ending, does not of itself reveal a moral purpose. It is the story-teller - the filmmaker whose morality shapes the moral of the story. In the liberal cultures of the developed world, the idea of the documentary filmmaker having a moral purpose is often treated with unease or suspicion. To the Ghanaian story-teller - even if recounting personal experiences - the moral purpose for telling the story, however, is of paramount importance. I therefore found it a challenge to try and incorporate a moral stance in the film without destroying the ambiguity and mystery of the story. I wanted to try and create a moral stance which was felt, but not articulated.

In Heart of Gold, I decided to work with three simple elements to explore this notion. They are in a sense the three non-diegetic elements which frame the story: the opening and closing image, and accompanying narration, the music and the colour schemes.

The first image of the film is that of my hand, in colour, opening up to reveal a shiny lump of gold. The narration - me - gives some simple matter of fact information about gold and its status in Ghanaian society, and in the Akim Abuakwa region, specifically. We then move into the story and at the end, we return to the same hand, opened, and also in colour, and most of the same information is repeated, before the hands closes up and the music starts. The relationship to this basic information I hope will have changed as a 
consequence of having gone through journey of the story. It is in this changing relationship that I hope the morality is revealed.

This is helped by the use of music. The music was specially commissioned, including the lyrics. It was tempting to choose some 'anthropologically correct' traditional music to reflect traditional culture, but the film is contemporary and the most important music for people of that region is Christian gospel music. It is the music of both enlightenment and moral instruction. I commissioned Lionel Lawson to create music with that feel to it and asked for specific lyrics to be included. The opening lyrics set the story up by referring to a young boy who found a lump of gold and didn't know what to do with it, while the lyrics at the end subtly suggest a view of gold as a divine gift to be treasured and treated with responsibility and respect.

\section{Texture}

Colour has already been mentioned in the context of the non-diegetic elements of the film. The core of the film - the story of Kwasi Akufo and his lump of gold - is in monochrome. Why tell the story in monochrome, if the real world is in colour? For me, the honest answer lies in the reality of the feeling. It felt right. It felt real. Reflecting on it intellectually, two strands of thoughts come to mind in the decision: whether factual or not, it is a story that is being told and the shifting from the non-diegetic colour to the diegetic monochrome helps remind us of that; second, I was interested in simplifying as many elements as possible in order to facilitate the transcendence of the surface reality to a deeper reality in which the mystical and the material elements coexist, indistinguishable from each other. Colour in this film (particularly when you have little control of these colours) could leave the audience stuck on the surface exotic beauty of Africa, for example, hindering their journey into the real reality of the film. The paradox of seeing real events unfold, but within the context of a constructed texture, might help take the audience somewhere different than the reality they are used to looking at.

\section{DISSEMINATION}

As mentioned earlier, the film will be made available on DVD, the full version of which will include interview extracts of participants in the film. Additionally, written reflections are available on the film's web site ${ }^{\text {xiv }}$.

Peer review is, of course, at the heart of research within the academy. The debate about how best to evaluate creative practice research is ongoing and perhaps this debate will never fully settle into a fixed definable entity, instead continually evolving to take account of an evolving art and discipline.

If I were to advise a peer reviewer to look at this research and evaluate the outcomes, I might suggest that the following questions be looked at: 
1. Do the research questions posed present an opportunity to add to our knowledge and understanding in the area being studied?

2. Is there evidence, in the completed film, that the research questions have been addressed?

3. In addressing the research questions in the finished film, is there evidence of there having been success in answering some of these questions?

4. If there are failures to answer some of the research questions, do those failures help to add to our understanding and knowledge of the issues the research questions pose?

5. Does any supporting material - visual, aural or written - encourage a better understanding of the research outcomes?

6. Does the methodological approach to the research seem rigorous?

7. Does the overall research package encourage further research?

\section{CONCLUSIONS}

The heart of the process of making a film, for me, is intuitive $\mathrm{e}^{\mathrm{xv}}$. An inner necessity, which I cannot explain, drives me to make them. I would even go as far as to say - as Rodin said about his relationship to stone and sculpture - the stories I tell already exist, my job, as an artist, is to see these stories and bring them into a tangible form. Intellectual reflection is just that: intellectual reflection. For me, the act of creation is not an intellectual act, but an act of inner necessity, faith, feeling and craft.

Intellectual reflection is, of course, in its proper place, very useful. Reflecting on my work in the context of research has helped me become aware of unconscious and intuitive tendencies, impulses and directions. It is not for my intellect to rule these impulses and tendencies, but to try to understand them, while allowing them free rein to take me where they want to take me, in order to, as Schumann says, '... send light into the darkness of men's hearts, ${ }^{\text {xvi }}$.

It is, perhaps, beyond the peer review process of academia to evaluate to what extent this has been achieved. My research aims are concerned with developing the language as an artist to achieve this. My peers will have to judge whether new knowledge and understanding is being added to our field of study. However, this research project has not only taught me things about the research experience, the process of creation and the form of 'documentary', but it has also opened up new questions and avenues. Some of these questions might include:

- How can one further evolve a new form in narrative filmmaking, which completely transcends (as opposed to blends) the distinctions between fact and fiction? How can this be done in a world where we like to define, categorise and distinguish?

- How can one incorporate notions of so called coincidence more fully into cinematic narratives? 
- How can one abstract reality - or the representation of reality - in order to reach the inner reality of people beyond the cause and effect of psychology.

- How can one deal with these themes without having to travel to visit traditional cultures? In other words, how, within our own culture which seems completely dominated by the empirical, can documentary find the cracks through which hidden realities can become palpable?

- What opportunities do developments in production and dissemination technologies offer?

Given what has been said about the artist's intuitive creative process, it is hard at this stage to qualify what precisely will be researched, without simply making it up. The questions remain shadows on the distant horizon. Not until intuition has taken me closer, will I be able to give them more shape and form. This is not very scientific; but then, the fact that the dominant methodological models for research are based on scientific precedents is, perhaps, the problem the creative artist working in academia is faced with.

\section{BIBLIOGRAPHY}

Bresson, R., 'Notes on Cinematography', Urizon, 1977.

Jung, C.G., 'Archaic Man' in 'Modern Man in Search of a Soul', Routledge, 1961.

Kandinsky, W., 'Concerning the Spiritual in Art', Tate, 2006.

\section{WEB}

Heart of Gold web site, One Day Films Limited, www.onedayfilms.com/films/heartofgold

Dr Erik Knudsen is currently the Programme Director of the MA in Documentary Production and the MA in Fiction Film Production in the School of Media Music and Performance at the University of Salford, Manchester. He is also Head of the Editing Department at the Escuela Internacional de Cine y Television in Cuba. Recent films include, Heart of Gold (40 min., documentary, 2006), Sea of Madness (86 min., fiction, 2006) and Brannigan's March (99 min., fiction, 2004).

\footnotetext{
i Available on 'Screenwork 2007', from www.onedayfilms.com and through the universities' library system.

ii The term 'poetic documentary' is used reluctantly, for the benefit of the reader who has not seen the film, in order to help make clear the departure from most common practices around documentary and also to hint at the film's sensitivities.

iii The terms 'inner' and 'outer' are used here as figures of speech and are not suggesting that the spiritual and the material can be divided into such definitions.
} 
${ }^{\text {iv }}$ It is worth noting that the Akans, who are the dominant ethnic group in this region, are matrilineal. Women hold enormous power, but when it comes to public expression including politics - this is one of the roles men perform.

${ }^{\mathrm{v}}$ This is a term used for semi-legal independent miners. Usually young men, they dig deep pits with rudimentary equipment in fields to mine for gold. It is dangerous work and one often hears of deaths associated with this sort of mining. Some fields are rendered unsuitable for farming, as they are littered with unmarked mining pits, often of 30 feet or more in depth.

${ }^{v i}$ To see more notes on the process, please visit www.onedayfilms.com/films/heartofgold where a blog from the research and shooting period is available.

vii It should perhaps be pointed out that like many developing countries, a schism is emerging in Ghana between the intellectual middle classes and the vast majority of the less educated populace, particularly where there is the added division of city and country. This is leading to differing value systems emerging, a theme touched on in the film. I was concerned with a rural situation, where there is still strong evidence of traditional life.

viii See the essay 'Archaic Man' in 'Modern Man in Search of a Soul', Jung, C.G., Routledge, 1961.

${ }^{\text {ix }}$ Note the differences in interpretation of the Bible by African congregations and European congregations. The simile or metaphor does not work in the same way across these cultures.

${ }^{x}$ Note what the main character in the film Heart of Gold calls me at the beginning of the film and at then at the end.

xi 'Krakatoa' (BBC 2006), 'Walking With Dinosaurs' (BBC 2001) and numerous others.

${ }^{x i i}$ I was, for example, fortuitously able to take advantage of a total solar eclipse during shooting. And, thinking as an Akan, I considered this not to be a mere coincidence, but providence to be incorporated into the reality of the film.

xiii There is a correlation between this approach and that of Robert Bresson, who uses the term 'models' to describe his characters. See 'Notes on Cinematography', Bresson, R., Urizon, 1977.

${ }^{\text {xiv }}$ www.onedayfilms.com/films/heartofgold

${ }^{\mathrm{xv}}$ Was it not Andre Gide who said, 'art is a collaboration between God and the artist and the more God has to do with it, the better'?

xvi 'Concerning the Spiritual in Art', Kandinsky, W., p. 10, Tate, 2006. 